\title{
Impact of Family History on Acute Appendicitis - An Iraqi Study at Baghdad Teaching Hospital
}

Tabarek Yaseen, Zahraa Qais, Zahraa Abass. ${ }^{1}$

\begin{abstract}
Background: Appendicitis is one of the most common causes of the acute abdomen worldwide, but many patients present with atypical signs and symptoms. The study aimed to evaluate the impact of positive family history in the diagnosis of appendicitis in a limited diagnostic setting. Methods: Gender matched case control study of ratio (1:2) was carried out from July 2016 to September 2016 with a sample size of 300 patients. Cases were patients presented in surgical department with acute abdominal pain diagnosed as having appendicitis for whom appendectomy was performed, while controls were hospital based with other abdominal problems. Data was collected using a questionnaire. Primary analysis was a Chi square ( $\times 2)$ test and the calculation of odds ratio (OR) for the association between final diagnosis of appendicitis and family history. Results: Females were $55 \%$ in both groups. Cases were younger than controls ( $27.05 \pm 12.58$ vs. $42.43 \pm 17.39$ years). Positive family history of appendectomy was higher among cases (66\%) than controls $(31.5 \%)$. The diagnosis of acute appendicitis was 3.8 times higher among those with positive family history of appendectomy and abdominal pain, with a sensitivity of $66 \%$ and a specificity of $66.4 \%$. Cases with more than one relative with family history of appendectomy, increased suspicion by 13 times when compared to those without family history. Conclusion: Positive family history of appendectomy in patients with acute abdominal pain and more than one relative with history of appendicitis can be considered as important parameters in the diagnosis of appendicitis in limited diagnostic setting.
\end{abstract}

Key Words: Acute Appendicitis, Family History, Risk Factor, Appendectomy, Emergency (Source: MeSH-NLM).

\section{Introduction}

The appendix is a blind muscular tube with mucosal, submucosal, muscular and serosal layers of length that varies between $7.5-10 \mathrm{~cm}$ and a diameter of 7-8 mm. It has the same structure of the colonic wall with more lymphoid tissue, about 200 lymphoid follicles that reach its peak during 10-30 years of age, decline after the 30 and disappear totally after 60 years of age.' Its importance comes from its tendency to inflame; it appears to play an immunological role by its lymphoid tissue and the production of immunoglobulins, especially immunoglobulin A (IgA). ${ }^{1} 7 \%$ of the world's population has the risk of acute appendicitis throughout their lives..$^{1-3}$ In the United States $1 / 7$ $1 / 17$ has acute appendicitis. 4

Appendicitis can occur in any age with highest incidence in late teenage years and early adulthood (205).5 Pathogenic stimulation can lead to lymphoid hypertrophy and luminal obstruction., 2,6 Immature immune system/defective immunity makes the occurrence of acute appendicitis rare in the extremes of age. 6

Appendectomy is the most common performed surgery in the emergency department; it constitutes $1-2 \%$ of all surgical operations.? It has a mortality rate of $0.1 \%$ that can reach $0.6 \%$ in the gangrenous type and may go above $20 \%$ in elderly as a result of the delayed diagnosis and intervention. The incidence rate among elderly is increasing, as well as the chance of complications. ${ }^{8}$ The Diagnosis is mainly clinical. 3 Accurate pre-operative diagnosis of acute appendicitis remains difficult especially for the atypical presentation, which is found in about $30-45 \%$ of patients with acute appendicitis. ${ }^{9-11}$ Misdiagnosis is more than $50 \%$ in elderly and children, and the chance of perforation increases with the delay of diagnosis. ${ }^{12}$ Diagnostic tools such as ultrasound, Computed Tomography scan (CT scan), Magnetic Resonance Imaging (MRI), radiology and laparoscopy may also be needed. An Alvarado score of seven or more is strongly predictive of acute appendicitis. Alvarado scoring system is easy, simple, cheap and aids in the diagnosis of acute appendicitis when other diagnostic techniques are unavailable. ${ }^{1,13}$ Negative appendectomy is still found, especially in a limited diagnostic setting, despite the development of diagnostic techniques. ${ }^{14}$ It is associated with unnecessary cost and complications.14 After 1995, there was a fall in the rate of negative appendectomies because of the CT scan and laparoscopy: in the United States, negative appendectomies had decreased from $14.7 \%$ in 1998 to $8.47 \%$ in 2007.6,15 Appendectomy is the main management of appendicitis, even if antibiotics do the job, prophylactic appendectomy is done.16,17 Obstruction of the lumen and infection are the main pathophysiological mechanisms. ${ }^{18}$ Genetics has its effect on incidence as well as severity of the disease through cytokines and antiinflammatory substances, like Interleukin-6 genes (IL6 genes), but environment seems to affect the role of genetics as in the hygiene theory. Evidence showed that Interleukin-8 (IL8), Interleukin-1B (IL1B), IL6, and Interleukin-6 Receptor (IL6R) are involved in the pathogenesis. 19,20 Complex segregation analysis supports a multifactorial or polygenic mode of heredity in about $56 \%$ of cases, with no evidence that supports the presence of a major gene.7,21-22 Serotonin level, which has a genetic determinant, as well as electrolytes to some extent, play a role in pathogenesis. ${ }^{23}$

The objective of the study is to evaluate the association between acute appendicitis and family history, to detect a difference between the null hypothesis, stating that positive family history is present in all groups, and the alternative hypothesis, stating that the proportion in the case group is higher than that in the control group.

Many studies showed that there is a familial predisposition to acute appendicitis and that half the variability of acute appendicitis is due to a genetic factor. Twin studies suggested that environmental factor and genetic factor contribute to $70 \%$ and $30 \%$, respectively, to the incidence of appendicitis. 3 Researchers concluded that a positive family history of acute appendicitis increased the potential risk in a patient even in the absence of the typical signs and symptoms.7,24,25 These studies dealt with family history but without testing the impact of the affected relatives' number on the diagnosis. In the current study, the sensitivity

\footnotetext{
${ }^{1}$ College of Medicine, University of Baghdad, Baghdad, Iraq.
}

About the Author: Tabarek Yaseen Hameed is a sixth year medical student of the College of Medicine, Baghdad University, Baghdad, Iraq, of a six-year program. She was one of the ten medical students invited as speaker at the $15^{\text {th }}$ Scientific Conference of the College of Medicine, University of Baghdad. She was ranked among the top five of her peer medical students and, in addition, was ranked the third at a national level in secondary school. 
and specificity, as well as the positive and negative predictive values of family history were compared to those of Alvarado score. This is the first study to provide such data about the Iraqi population.

As mentioned before, up to $45 \%$ of those with appendicitis have atypical presentation, and misdiagnosis may reach $50 \%$ in age extremes. These, in addition to negative appendectomy with its complications and delayed management with its mortality and morbidity rates, are more common in the limited diagnostic setting. Predictors like a family history of acute appendicitis, especially when more than one relative is affected, as well as simple diagnostic tools like the complete blood count and ultrasound, can support the clinical diagnosis.

The aim of the study is to evaluate the impact of a positive family history on the diagnosis of appendicitis in a limited diagnostic setting.

\section{Methods}

A gender-matched case-control study of a 1:2 ratio was carried out from July 2016 to September 2016 at Baghdad Teaching Hospital, Medical City Health Directorate. A convenient sample of 300 patients was used, 100 of them were present in the surgical department with acute abdominal pain (cases), for whom appendectomy was performed after the diagnosis of acute appendicitis was established, while the other 200 presented to the medical/surgical department with other abdominal problems either with/without abdominal pain (hepatic, pancreatic, gynecological, urological and renal problems), those were included as controls.

The controls shared symptom/sign with appendicitis; this made the study of the impact of a positive family history of appendectomy on the diagnosis of acute appendicitis more realistic and applicable, and reduced recall and response bias among the control group.

To detect a difference between the null hypothesis, stating that positive family history is present in all groups, and the alternative hypothesis, stating that the proportion in the case group is higher than the control group, all patients, who presented at the time of data collection and agreed to participate, were included in the study according to the diagnosis, while anyone with a previous history of appendectomy and unknown family history of appendectomy was excluded. Patients were initially divided according to their diagnosis into two groups (cases, controls), then control groups were divided into two subgroups according to the presence of abdominal pain, then the two groups were divided into three subgroups according to the number of relatives with positive family history of appendectomy due to acute appendicitis (negative family history, one relative with history of appendectomy, more than one relative).

A questionnaire form was prepared by the authors to collect data from both cases and controls through a direct interview with each participant; the form included: age, sex, definite diagnosis of patient's problem, presence/absence of abdominal pain, family history of appendectomy (mother, father, siblings, uncle, aunt, cousin, grandparent) and the number of relatives with a positive family history of appendectomy.

Data were analyzed using descriptive statistics with SPSS version 18. Categorical variables were presented as frequency and relative frequency. Chi-square test was used to test the significant associations between categorical variables. Odds Ratio (OR) and $95 \%$ Confidence Interval $(\mathrm{Cl})$ were used to measure the degree of association between cases and controls. P-Value of less than 0.05 was considered statistically significant.

\section{Ethical Consideration}

official agreements to perform the research were obtained from College of Medicine - University of Baghdad and Medical City Health Directorates (approval number 1115/23.03.2016).

The aims of the study were explained to each participant and their oral consent was taken.

\section{Results}

To predict the association between family history and incidence of acute appendicitis, 100 patients (mean age $27.1 \pm 12.6$ years), who were diagnosed with acute appendicitis and for whom appendectomy was performed, were compared with 200 patients (mean age $42.4 \pm 17.4$ years), who were diagnosed with any cause of acute abdominal pain or another abdominal problem except acute appendicitis, among both groups females formed $55 \%$.

Regarding age, two-thirds of the cases (66\%) were between 10-29 years compared to only $29 \%$ among controls, and the association was statistically significant ( $x^{2}$ test $=63.9, d f=4, P<0.0001$ ) (Table 1). As for family history of appendectomy, Table 2 shows that two thirds (66\%) of the cases had a positive family history of appendectomy compared to $31.5 \%$ among the controls, and the association was statistically significant $\left(X^{2}=32.375, d f=1, P<0.0001\right)$ with $66 \%$ sensitivity, $68.5 \%$ specificity, a positive predictive value of $51.2 \%$, and a negative predictive value of $80.1 \%$. The patients with positive family history had 4.2 times risk of being a case of acute appendicitis compared to those with negative family history $(\mathrm{OR}=4.2,95 \% \mathrm{Cl}: 2.5-7.0$, Table 2$)$.

Table 1. Distribution of Cases and Controls by Age Groups* in Years

\begin{tabular}{ccccc}
\hline $\begin{array}{c}\text { Ages } \\
\text { Groups } \\
\text { (years) }\end{array}$ & \multicolumn{2}{c}{$\begin{array}{c}\text { Patients with appendicitis } \\
\text { (Cases) }\end{array}$} & \multicolumn{2}{c}{$\begin{array}{c}\text { Hospital-based patients } \\
\text { (Controls) }\end{array}$} \\
\hline $19-0 \mathrm{ct}$ & No. & $\%$ & No. & $\%$ \\
\hline $20-29$ & 34 & 34 & 10 & 5 \\
\hline $30-39$ & 19 & 32 & 48 & 24 \\
$40-49$ & 8 & 19 & 39 & 19.5 .0 \\
\hline 50 & 7 & 8 & 32 & 16 \\
\hline Total & 100 & 7 & 71 & 35.5 .0 \\
\hline
\end{tabular}

Legend: *Statistically significant association; $\chi^{2}$ test $=63.9, d f=4, P<0.0001$, No.=number

Table 2. Distribution of Family History of Appendectomy within Case and Control Groups.

\begin{tabular}{ccccccc}
\hline $\begin{array}{c}\text { Family } \\
\text { history of } \\
\text { appendecto } \\
\text { my }\end{array}$ & No. & $\%$ & No. & $\%$ & & $\begin{array}{c}\text { Odds ratio } \\
(95 \%\end{array}$ \\
Positive & 66 & 66 & 63 & 31.5 & & $\begin{array}{c}\text { Controls } \\
\text { Confidence } \\
\text { Interval) }\end{array}$ \\
Negative & 34 & 34 & 137 & 68.5 & $<0.0001$ & $\begin{array}{c}4.221 \\
\text { Total }\end{array}$ \\
\hline 100 & 100 & 200 & 100 & &
\end{tabular}

Legend: Sensitivity $66 \%$, specificity $68.5 \%$, positive predictive value $51.2 \%$, negative predictive value $80.1 \%$, No.=number.

Then, we divided the control group into two subgroups, a subgroup of 134 out of 200 patients had abdominal pain; in this subgroup 45 of 134 $(33.5 \%)$ had with a positive family history. The comparison was significant as the ( $p<0.0001, O R=3.8 ; 95 \% \mathrm{Cl}: 2.22$ to 6.63 ) with $66 \%$ sensitivity, $66.4 \%$ specificity, a positive predictive value of $59.4 \%$, and a negative predictive value of $72.3 \%$ (Table 4 ).

The second subgroup of 66 out of 200 patients did not have abdominal pain; in this subgroup, $27.27 \%$ were with a positive family history. The comparison was also statistically significant as the $(p<0.0001,0 R=5.0$; $95 \% \mathrm{Cl}: 2.56$ to 10.03 ) with $66 \%$ sensitivity, $72 \%$ specificity, a positive predictive value of $78.5 \%$, and a negative predictive value $58.5 \%$.

After that, case and control groups were divided according to the number of relatives with a positive family history of appendectomy into three subgroups (Negative family history, One member with positive history, More than one member with positive history); comparing those with a negative family history to those having one member with a positive history then to those with more than one member with a 
positive history, the results were statistically significant as ( $p<0.0001$, OR=3.4; $95 \%$ IC: 1.99 to $5.80,59 \%$ sensitivity, $70.2 \%$ specificity, a positive predictive value $45.8 \%$, and a negative predictive value $80.1 \%$; p $<0.0001$, $\mathrm{OR}=13.7 ; 95 \% \mathrm{Cl}: 4.72$ to $39.76,33.3 \%$ sensitivity, $96.5 \%$ specificity, a positive predictive value $77.2 \%$, and a negative predictive value $80.1 \%$, respectively. Table. $3 a, 3 b$ ).

Table 4. Distribution of Family History of Appendectomy and Presence of Abdominal Pain

\begin{tabular}{|c|c|c|c|c|c|c|}
\hline \multirow[t]{2}{*}{$\begin{array}{l}\text { Family history of } \\
\text { appendectomy }\end{array}$} & \multicolumn{2}{|c|}{ Cases } & \multicolumn{2}{|c|}{$\begin{array}{c}\text { Control } \\
\text { subgroup with } \\
\text { abdominal } \\
\text { pain }\end{array}$} & \multirow[t]{2}{*}{$\begin{array}{c}\mathrm{P} \text { - } \\
\text { value }\end{array}$} & \multirow{2}{*}{$\begin{array}{l}\text { Odds } \\
\text { ratio } \\
(95 \% \\
\left(I^{*}\right)\end{array}$} \\
\hline & No. & $\%$ & No. & $\%$ & & \\
\hline Positive & 66 & 66 & 45 & 33.5 & \multirow{3}{*}{$<0.001$} & \multirow{3}{*}{$\begin{array}{c}3.839 \\
(2.221- \\
6.637)\end{array}$} \\
\hline Negative & 34 & 34 & 89 & 66.5 & & \\
\hline Total & 100 & 100 & 134 & 100 & & \\
\hline
\end{tabular}

Legend: Sensitivity $66 \%$, specificity $66.4 \%$, positive predictive value $59.4 \%$, negative predictive value $72.3 \%$. ${ }^{\star} \mathrm{Cl}$ : Confidence Interval.

\section{Discussion}

Appendicitis is one of the most common causes of acute abdomen. In addition, appendectomy is the most commonly performed surgery in the emergency department; despite that, delayed diagnosis and management as well as negative appendectomy along with its complications especially adhesions and its effect on female fertility are still found particularly in limited diagnostic settings. The current study aimed to test the impact of a positive family history of appendicitis on the diagnosis of acute appendicitis. It has found that a positive family history of appendectomy due to appendicitis in those with acute abdominal pain should be considered as an important parameter in the diagnosis as it was associated with three times increased risk compared to those with acute abdominal pain who a had negative family history. Moreover, those having more than one relative with a positive history are 13 times more susceptible to have acute appendicitis in comparison to those with a negative family history.

Initially, patients who presented with appendicitis were 4 times more likely to have a positive family history than those presenting with other diagnoses, whether they did or did not have abdominal pain. In Drescher et al study there was 1.9 times increased risk, which was statistically significant; this difference may be attributable to differences between the two samples in socioeconomic state, which made the population with a relatively lower socioeconomic state or lower hygiene policies less likely to have acute appendicitis unless a stronger familial tendency is found according to the hygiene theory $6 ., 25$ There was a 3.8 times increased risk in those presenting with both acute abdominal pain and positive family history of appendectomy in comparison to those presenting with abdominal pain without a positive family history of appendectomy, a result similar to the study of Ergul et al., with a 3.1 times increased risk while the risk increased by 1.7 times in the study of Drescher et al., which is still statistically significant.7,25 Another study demonstrated a familial aggregation and a polygenic transmission pattern in a retrospective analysis of families of 80 patients with appendicitis compared to families of matched controls. They found that the relative risk was 10; in other words, the chance of appendicitis was 10 times greater in a child with at least one relative with reported appendectomy, compared to a child with no affected relatives. ${ }^{21}$ Gauderer et al., found that children who have appendicitis are twice as likely to have a positive family history of acute appendicitis than those with lower abdominal pain without appendicitis, and 3 times increased risk when compared to controls without abdominal pain.24 Brender et al., found in their case-control study that parents of patients with appendicitis were approximately $10 \%$ more likely to have a positive family history of appendicitis than parents of control children. ${ }^{26}$
A Japanese study found that $40 \%$ of children in which both parents had acute appendicitis are affected and $20 \%$ of children with one parent having acute appendicitis are affected with acute appendicitis. ${ }^{27}$ All these studies support the familial tendency of appendicitis, this tendency may be explained by environmental factors such as a specific bacterial infection, certain food habits and genetic difference in resistance to bacterial infections and inflammatory response.7 Another study, performed by Daniel C., found out that, in a family pedigree that had 16 members with acute appendicitis, 15 cases were with retrocecal appendix. The same conclusion was reached by Shperber et al..$^{28}$

As acute appendicitis is a common disease, $7 \%$ of the world's population is at risk of being affected during their life. The presence of one relative with a positive history of appendectomy may be by chance; cases and controls were divided according to the number of the affected relatives (negative family history, one relative with positive family history of appendectomy, more than one relative with positive family history), this had not been taken into account by other researchers, as a result, those presented with abdominal pain and more than one relative with positive history of appendectomy increased suspicion of having acute appendicitis by 13 times, while those presented with abdominal pain and one relative with positive history of appendectomy increase the suspicion by 3 times when compared to those with negative family history.

When only family history was used as a diagnostic test in those with abdominal pain, its sensitivity was $66 \%$, specificity was $66.4 \%$, its positive predictive value was $59.4 \%$, and its negative predictive value was $72.3 \%$, which is consistent with that of Ergul et al., study (The sensitivity was $68.9 \%$, specificity was $75.4 \%$, positive predictive value was $68.9 \%$ and negative predictive value was $75.4 \%$ ). When family history is used as diagnostic test, its sensitivity and specificity are close to those of Alvarado score test (sensitivity $91.5 \%$ and specificity $60.5 \%) .7$ It is still uncertain why family history of appendectomy is not used as diagnostic test, especially in the conditions where there are limited facilities.

In contrast to other studies like Drescher et al., study during 2013, in which females formed $46.5 \%$ in the cases group and $61.5 \%$ in the control group, in this study, the gender was matched, females formed $55 \%$ in both groups so that the effect of the gender factor was limited as much as possible (the incidence was slightly more in males than females $1.1-3.1) .2,25$

Regarding age, the mean age was $27.1 \pm 12.6$ years in the cases group, and $42.4 \pm 17.4$ years in those who were included as controls. This difference may be attributed to the controls being hospital-based; besides, many were excluded from the control group because of their previous history of appendectomy. In our study, more controls with no previous history of appendectomy were older than the age of the peak incidence of appendicitis; this gives more confidence about those included in the control group as the prevalence of appendicitis decreases with age. The age differences can be seen in other studies like Ergul et al., and Drescher et al., (31\% of cases and $20.8 \%$ of controls were aged less than 30 years), while in this study, $66 \%$ of cases and $29 \%$ of controls were less than 30 years.7.25

Duration of the study was the only limitation, otherwise the sample size could have been larger. By measuring Alvarado scoring sensitivity and specificity and comparing it to that of family history of acute appendicitis, the groups could be divided into males' and females' subgroups to overcome the slight difference between genders. The small sample size was overcome by choosing case-control as the type of the study, and the cases to control ratio was made 1:2; it is known that each increment in the case to control ratio is associated with an increment in the study power. 
Table 3a. Distribution of Cases and Controls by the Number of Relatives with Positive Family History of Appendicitis.

\begin{tabular}{|c|c|c|c|c|c|c|c|}
\hline \multirow{2}{*}{$\begin{array}{l}\text { Family history of } \\
\text { appendectomy }\end{array}$} & \multicolumn{2}{|c|}{ Cases } & \multicolumn{2}{|c|}{ Controls } & \multirow{2}{*}{$P$ value } & \multirow{2}{*}{$\begin{array}{l}\text { Chi square } \\
{[D f(1)]}\end{array}$} & \multirow{2}{*}{$\begin{array}{l}\text { Odds ratio ( } 95 \% \\
\text { confidence } \\
\text { interval) }\end{array}$} \\
\hline & No. & $\%$ & No. & $\%$ & & & \\
\hline $\begin{array}{l}\text { One member with positive } \\
\text { family history }\end{array}$ & 49 & 59 & 58 & 29.74 & $<0.0001$ & 21.1 & $3.404(1.995-5.809)$ \\
\hline Negative family history & 34 & 40.96 & 137 & 70.25 & & & \\
\hline Total & 83 & 100 & 195 & 100 & & & \\
\hline
\end{tabular}

Legend: Sensitivity $59 \%$, specificity $70.2 \%$, positive predictive value $45.8 \%$, negative predictive value $80.1 \%$, No=number.

Table $3 b$. Distribution of Cases and Controls by the Number of Relatives with Positive Family History of Appendicitis.

\begin{tabular}{|c|c|c|c|c|c|c|c|}
\hline \multirow{2}{*}{$\begin{array}{l}\text { Family history of } \\
\text { appendectomy }\end{array}$} & \multicolumn{2}{|c|}{ Cases } & \multicolumn{2}{|c|}{ Controls } & \multirow{2}{*}{$P$ value } & \multirow{2}{*}{$\begin{array}{l}\text { Chi square } \\
\text { [Df (1)] }\end{array}$} & \multirow{2}{*}{$\begin{array}{c}\text { Odds ratio } \\
\text { (95\% confidence } \\
\text { interval) }\end{array}$} \\
\hline & No. & $\%$ & No. & $\%$ & & & \\
\hline $\begin{array}{l}\text { More than one member } \\
\text { with positive family } \\
\text { history }\end{array}$ & 17 & 33.33 & 5 & 3.52 & $<0.0001$ & 33.021 & $13.7(4.720-39.761)$ \\
\hline Negative family history & 34 & 66.66 & 137 & 96.5 & & & \\
\hline Total & 51 & 100 & 142 & 100 & & & \\
\hline
\end{tabular}

Legend: Sensitivity $33.3 \%$, specificity $96.5 \%$, positive predictive value $77.2 \%$, negative predictive value $80.1 \%$, No=number, $d f=d e g r e e$ of freedom

In conclusion, positive family history of appendectomy in patients with acute abdominal pain should be considered as an important parameter in the diagnosis of appendicitis in a limited diagnostic setting as it increases the risk of having appendicitis by three times compared to those with negative family history.
Increasing the number of relatives with positive history of appendectomy is associated with more risk of appendicitis compared to those with one relative with positive history of appendectomy. 


\section{References}

1. Williams NS, Bailey H, Bulstrode CJ, Love RM, O'Connell PR. Bailey थt Love's Short Practice of Surgery. $25^{\text {th }}$ ed. London: CRC Press; 2008.

2. Pieper R, Kager L. The incidence of acute appendicitis and appendectomy. An epidemiological study of 971 cases. Acta Chir Scand. 1982;148(1):45-9.

3. Heydari A, Zeydi AE. Can Family History Be Used As a Predictor in Patients with Suspected Acute Appendicitis at the Emergency Department?. Bull Emerg Trauma. 2014 Apr;2(2):99-100.

4. Cwynn LK. The diagnosis of acute appendicitis: clinical assessment versus computed tomography evaluation. J Emerg Med. 2001 Aug;21(2):119-23.

5. Buckius MT, McGrath B, Monk J, Grim R, Bell T, Ahuja V. Changing epidemiology of acute appendicitis in the United States: study period 1993-2008. J Surg Res. 2012 Jun 15;175(2):185-90. doi: 10.1016/j.jss.2011.07.017. Epub 2011 Aug 9.

6. Barlas Sulu. Demographic and Epidemiologic Features of Acute Appendicitis. In: Lander A, editor. Appendicitis - A Collection of Essays from Around the World. Rijeka: InTech; 2012. p. 169-178.

7. Ergul E, Ucar AE, Ozgun YM, Korukluoglu B, Kusdemir A. Family history of acute appendicitis. J Pak Med Assoc. 2008 Nov;58(11):635-37.

8. Harbrecht BC, Franklin CA, Miller FB, Smith JW, Richardson JD. Acute appendicitis - not just for the young. Am J Surg. 2011 Sep 30;202(3):286-90.

9. Nitoń T, Górecka-Nitoń A. [Usefulness of imaging examinations in preoperative diagnosis of acute appendicitis]. Wiad Lek. 2014;67(4):548-53. Polish.

10. Murphy EEK, Berman L. Clinical Evaluation of Acute Appendicitis. Clin Pediatr Emerg Med. 2014 Sep 30;15(3):223-30.

11. Flum DR, McClure TD, Morris A, Koepsell T. Misdiagnosis of appendicitis and the use of diagnostic imaging. J Am Coll Surg. 2005 Dec;201(6):933-9.

12. Papandria D, Goldstein SD, Rhee D, Salazar JH, Arlikar J, Corgy A, et al. Risk of perforation increases with delay in recognition and surgery for acute appendicitis. I Surg Res. 2013 Oct;184(2):723-9. doi: 10.1016/j.jss.2012.12.008. Epub 2012 Dec 27.

13. Althoubaity FK. Suspected acute appendicitis in female patients. Trends in diagnosis in emergency department in a University Hospital in Western region of Saudi Arabia. Saudi Med J. 2006 Nov;27(11):1667-73.

14. Webb EM, Nguyen A, Wang ZJ, Stengel JW, Westphalen AC, Coakley FV. The negative appendectomy rate: who benefits from preoperative CT?. Am J Roentgenol. 2011 Oct;197(4):861-6.
15. Seetahal SA, Bolorunduro OB, Sookdeo TC, Oyetunji TA, Greene WR, Frederick W, et al. Negative appendectomy: a 10-year review of a nationally representative sample. Am J Surg. 2011 Apr;201(4):433-7.

16. Shimi SM. Appendicitis and Appendicectomy. In: Elgeidie A, editor. Updated Topics in Minimally Invasive Abdominal Surgery. Rijeka: InTech; 2011. p. 137-156.

17. Chamisa I. What Is the Role of Conservative Antibiotic Treatment in Early Appendicitis? In: Lander A editor. Appendicitis - A Collection of Essays from Around the World. Rijeka: InTech; 2012. p. 95-106.

18. Kumar V, Abbas AK, Aster JC. Robbins Basic Pathology. Elsevier Saunders $.9^{\text {th }}$ ed. Philadelphia: Elsevier Saunders; 2013.

19. Sarsu SB, Yılmaz ŞC, Bayram A, Denk A, Kargun K, Sungur MA. Polymorphisms in the IL- 6 and IL-6R receptor genes as new diagnostic biomarkers of acute appendicitis: a study on two candidate genes in pediatric patients with acute appendicitis. Ital I Pediatr. 2015 Dec 29;41:100.

20. Arlt A, Bharti R, Ilves I, Häsler R, Miettinen P, Paajanen $H$, et al. Characteristic changes in microbial community composition and expression of innate immune genes in acute appendicitis. Innate Immun. 2015 Jan;21(1):30-41. Epub 2013 Dec 11.

21. Basta M, Morton NE, Mulvihill IJ, Radovanović Z, Radojicić C, Marinković D. Inheritance of acute appendicitis: familial aggregation and evidence of polygenic transmission. Am J Hum Genet. 1990 Feb;46(2):377-82.

22. Andersson N, Griffiths H, Murphy J, Roll J, Serenyi A, Swann I, et al. Is appendicitis familial?. Br Med J. 1979 Sep 22;2(6192):697-8.

23. Petroianu A. Acute Appendicitis - Propedeutics and Diagnosis. In: Khatami $M$, editor. Inflammatory Diseases - Immunopathology, Clinical and Pharmacological Bases. Rijeka: InTech; 2012. p. 171-200.

24. Cauderer MW, Crane MM, Green JA, DeCou JM, Abrams RS. Acute appendicitis in children: the importance of family history. J Pediatr Surg. 2001 Aug;36(8):1214-7.

25. Drescher MJ, Marcotte S, Grant R. Family history is a predictor for appendicitis in adults in the emergency department. West J Emerg Med. 2012 Dec;13(6):468-71.

26. Brender ID, Marcuse EK, Weiss NS, Koepsell TD. Is childhood appendicitis familial? Am J Dis Child. 1985 Apr;139(4):338-40.

27. Hiraiwa $H, U$ memoto $M$, Take H. Prevalence of appendectomy in Japanese families. Acta Paediatr Jpn. $1995 \mathrm{Dec} ; 37(6): 691-3$.

28. Shperber $Y$, Halevy A, Oland J, Orda R. Familial retrocaecal appendicitis. J R Soc Med. 1986 Jul; 79(7): 405-406.

\section{Acknowledgments}

Authors thankful for Dr. Essam Munir for his continuous big help, Zahraa Arkan for help in data collection and Dr. Batool A. Ch. Yassin. Conflict of Interest Statement at Funding

The Authors have no funding, financial relationships or conflicts of interest to disclose.

Author Contributions

Conception and design the work/idea: TY, ZQ, ZA. Collect data/obtaining results: TY, ZQ, ZA. Analysis and interpretation of data: TY. Write the manuscript: TY, ZQ. Critical revision of the manuscript: TY. Approval of the final version: TY, ZQ, ZA. Statistical advice: TY.

Cite as:

Yaseen T, Qais Z, Abass Z. Impact of Family History on Acute Appendicitis - An Iraqi Study at a Baghdad Teaching Hospital. Int J Med Students. 2018 MayAug;6(2):47-51. 